\title{
Screening of Coxsackie B virus infection among patients with myocarditis and dilated cardiomyopathy using Serion Elisa classic Coxsackie virus IgM in Chennai, Tamilnadu, South India
}

\author{
K. Bharathi ${ }^{1, *}$, Jeevan Malaiyan ${ }^{2}$ \\ ${ }^{1}$ Senior Assistant Professor, ${ }^{2}$ Assistant Professor, Dept. of Microbiology, ${ }^{1}$ Government Sivagangai Medical College, Sivagangai, \\ ${ }^{2}$ Sri Muthukumaran Medical College Hospital and Research Institute, Chikkarayapuram, Chennai, Tamil Nadu, India \\ *Corresponding Author: \\ Email: drbharathimd@yahoo.co.in

\begin{abstract}
s
Almost $70 \%$ of the myocarditis and dilated cardiomyopathy (DCM) cases are found to be caused by Enterovirus genus, the majority of these infections were caused by coxsackie virus B (CVB) group. There is no recent data available on extra-intestinal infection particularly myocarditis and DCM caused by this virus in south India. Presence of IgM antibody specific for CVB in myocarditis and DCM patients were detected using SERION ELISA. The prevalence of Coxsackie B virus among myocarditis and dilated cardiomyopathy patients was found to be $75.75 \%$ when tested using an immunoassay specific for IgM antibodies. The mortality rate among study population is found to be $6 \%$.
\end{abstract}

Keywords: Coxsackie B virus, Myocarditis, Dilated cardiomyopathy, Serion elisa.

\section{Introduction}

Coxsackie viruses are members of Picornaviridae family are non-enveloped, linear, positive sense single stranded RNA viruses belonging to the genus Enterovirus. Coxsackie virus was first isolated from human feces in the town of Coxsackie, New York, in 1948 by G. Dalldorf (Dalldorf et al., 1948 and Dallford et al., 1949). The salient features of this virus group are they have the same physical, chemical and biological properties and a similar epidemiologic pattern (Modlin et al., 1990). Infection is usually spread by the faecaloral route, although the virus is also spread by droplets expelled by infected individuals from specimens such as saliva, fluid in blisters and nasal secretions. The portal of entry is through the respiratory tract (oropharynx) and the gastrointestinal tract, where they infect and multiply in the oropharyngeal and intestinal epithelium. From there, the virus is carried by the bloodstream to the target cells. Coxsackie viruses infect host cells and cause lysis of host cells. Coxsackie virus causes various clinical manifestations, which include summer flu, febrile and catarrhal infections, vesicular pharyngitis, aseptic meningitis, meningoencephalitis, hand foot and mouth disease, pleurodynia, carditis (myocarditis, pericarditis, myopericarditis, encephalomyocarditis), maculopapular exanthema, hepatitis and acute haemorrhagic conjunctivitis. Although people of any age can get infected, the majority of patients identified with Coxsackie infection are children. Pregnant women can transmit Coxsackie virus to their newborns, which may pose serious teratogenic effects for the newborns. Coxsackie viruses are classified into group A and group B based on their effects on newborn mice. Group A has 24 serotypes having distinct proteins on the viral surface and $B$ has 6 serotypes. Coxsackie A and B virus can cause extra- intestinal infections such as meningitis, myocarditis and pericarditis.

Almost $70 \%$ of the myocarditis and dilated cardiomyopathy (DCM) cases are found to be caused by Enterovirus genus, the majority of these infections were caused by coxsackie virus B (CVB) group (Jin et al., 1990). This necessitates the importance of monitoring for coxsackie virus infection in these patients. There is no recent data available on extraintestinal infection particularly myocarditis and DCM caused by this virus in south India. Hence this study was done to detect the presence of IgM antibody specific for CVB in myocarditis and DCM patients using SERION ELISA kit in order to bring out the prevalence of the CVB in these patients in Chennai, South India.

\section{Materials and Methods}

A total of 33 blood samples were collected between December 2010 and June 2012 from patients admitted to the Department of Cardiology, Rajiv Gandhi Government General Hospital, Chennai. Patients who were admitted with fever and sudden onset of cardiac dysfunction with suspicion for viral myocarditis were considered for the study. Blood samples were collected from patients with symptoms such as fever, sudden difficulty in breathing which is progressive in nature, malaise, chest pain, palpitations, edema and cardiac failure. The patient medical history and demographic details of the patients including present history, past history, laboratory investigations, and treatment given were noted. Patients with underlying valvular heart disease, myocardial infarction, features suggesting post-surgical infective endocarditis were excluded from the study. $2 \mathrm{ml}$ of blood sample was collected through cephalic vein 
puncture using aseptic precautions. Blood was collected in a vacutainer and was transported to the laboratory immediately. Blood samples were allowed to clot. The samples were then centrifuged at $3000 \mathrm{rpm}$ for 15 minutes. The serum was carefully pipetted in to a sterile tube without any RBC contamination and used for the detection of IgM antibody against coxsackie B virus by Serion ELISA kit. The serum samples were stored at $20^{\circ} \mathrm{C}$ until use to avoid thermal inactivation.

Serion ELISA classic coxsackie B virus Ig M kit (SERION ELISA KIT) was used for the detection of viral myocarditis. It is a qualitative test detecting Ig M antibodies produced against coxsackie B viral infections. In the serion ELISA classic Coxsackie virus kit highly purified, heat-treated Coxsackie viruses type B1 and B5 are bound to the solid phase. These two serotypes are described as sufficiently cross-reactive to enable heterotypical diagnosis of Coxsackie virus infection.

The serum sample requires pretreatment before carrying out the ELISA. This is done in order to increase the sensitivity and specificity of the test procedures. Rheumatoid factors are autoantibodies belonging to the IgM - class, which preferably bind to $\mathrm{IgG}$ - immune complexes. The presence of non-specific IgM - antibodies such as rheumatoid factors can lead to false-positive results in the IgM - assay. In addition there is possibility of weak binding pathogen specific IgM - antibodies being displaced by stronger binding IgG antibodies leading to false negative results during IgM-detection.

Therefore it is necessary to pretreat samples with rheumatoid factor absorbent prior to IgM detection. The rheumatoid factor absorbent must be diluted in dilution buffer in 1:4 ratio. To the diluted rheumatoid factor absorbent the patients sample is added in 1:100 ratio.

To the microtitre plate $100 \mu$ l of diluted sample, standard serum and controls were added into the appropriate wells and incubated for one hour at $37^{\circ} \mathrm{C}$ in moist chamber. One well was reserved for substrate blank. After incubation all wells were washed with $300 \mu \mathrm{l}$ washing solution and the incubation solution was aspirated. This washing procedure was repeated three to four times and dried by tapping the microtitre plate on a paper towel. $100 \mu \mathrm{l}$ of IgM conjugate was added to all the wells except substrate blank and incubated for 30 minutes at $37^{\circ} \mathrm{C}$ in moist chamber. After incubation all the wells were washed with $300 \mu$ l washing solution for three to four times and dried by tapping the microtitre plate on a paper towel. $100 \mu \mathrm{l}$ substrate solution was added to each well including the well for substrate blank and incubated for 30 minutes at $37^{\circ} \mathrm{C}$ in moist chamber. $100 \mu$ stopping solution was added to each well and microtitre plate was gently vibrated to mix well. OD was read within 60 minutes at $405 \mathrm{~nm}$ against substrate blank, and the reference wave length was between $620 \mathrm{~nm}$ and $690 \mathrm{~nm}$.

\section{Qualitative Evaluation}

To fix the cut-off ranges the mean value of the measured standard OD was multiplied with the numerical data of the certificate of quality control $\mathrm{OD}=0.502 \times \mathrm{MW}(\mathrm{STD})$ with upper cut-off $\mathrm{OD}=0.352 \times \mathrm{MW}(\mathrm{STD})$ with lower cut-off

\section{Results}

A total of 33 patients had consented for this study. Out of 33 samples collected 16(48.5\%) were females and $17(51.5 \%)$ were males.

25/33 were found to be positive for Coxsackie B virus IgM antibodies using SERION ELISA kit.

\section{Calculation of Results}

The OD values of samples $1-33$ is calculated as per SERION ELISA KIT Protocol.

\section{To calculate the cut off range the following formula was applied.}

$\mathrm{OD}=0.502 \times \mathrm{MW}(\mathrm{STD})$ with upper cut-off

$\mathrm{OD}=0.352 \times \mathrm{MW}(\mathrm{STD})$ with lower cut-off.

In case of samples 1 to 20 the cut off range was found to be 0.097 to 0.139 , based on which $13 / 20$ samples were positive.

In case of samples 21 to 33 the cut off range was found to be 0.091 to 0.13 , based on which $12 / 13$ samples were positive.

Of 33 samples collected 25(75.75\%) were positive for IgM antibody of Coxsackie B virus (Fig. 1). Among the 25 positive samples $2(8 \%)$ were children and $23(92 \%)$ were adults. Among 25 positive samples 13(52\%) were females and 12(48\%) were males (Fig. 2). Diabetes mellitus, Systemic hypertension, Rheumatoid arthritis and Coronary artery disease were some of the comorbid conditions associated with these patients. The patients in this study were managed with bed rest, for symptoms like shortness of breath digoxin and diuretics were given. For moderate to severe dysfunction inotropes such as dopamine and dobutamine were given followed by ACE inhibitors (captopril, lisinopril). Comorbid conditions like diabetes mellitus, coronary artery diseases were treated. 2 out of 33(6.06\%) patients expired within two days of admission and both of them were females. 


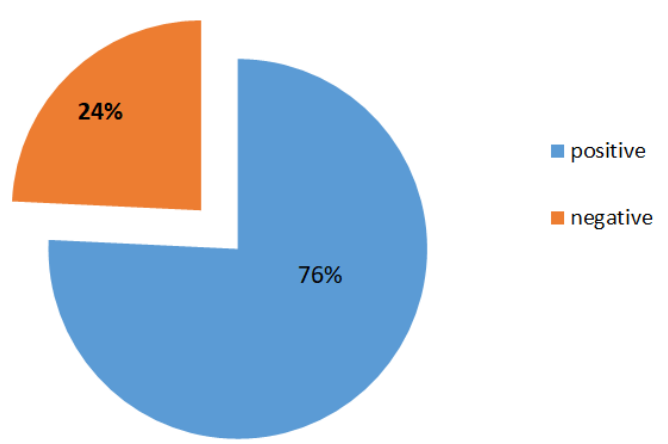

Fig. 1: Overall seropositivity of Coxsackie B IgM by Elisa

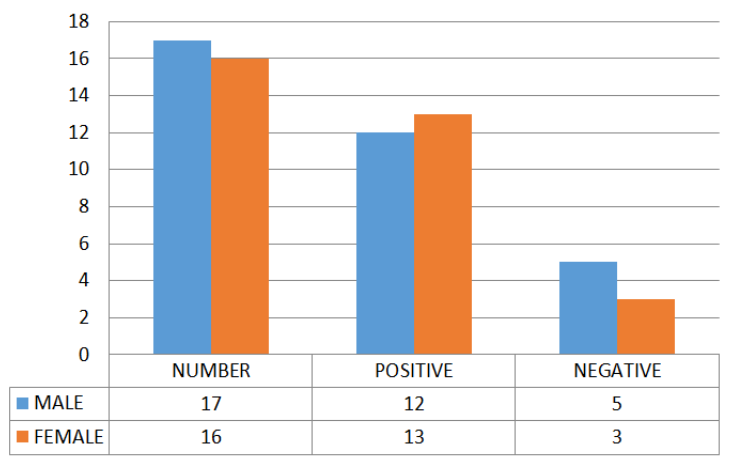

Fig. 2: Genderwise distribution

\section{Discussion}

Coxsackie virus group B was reported to be the major etiological agent of Enteroviral myocarditis. Elevated antibody titres in dilated cardiomyopathy, progressive clinical syndromes with viral myocardiitis culminating in DCM and high-incidence of heart failure are the some of the factors which links the Coxsackie virus infection with the Dilated Cardiomyopathy. Coxsackie virus infections can be confirmed by virus isolation and identification by cell culture methods or serologically by detection of specific antibiodies. Isolation rate of Coxsackie virus by cell culture during late stages of the cardiac disease like cardiomyopathies was found to be low (Why et al., 1994; Li et al., 2000; Zhang et al., 2004). Serological tests for detection of the group specific antibodies are useful diagnostic tools for specific detection of the stages of the Coxsackie virus myocardial infection. Large number of samples can be tested in short duration of time. Many standard serological methods are available for the detection of the rise in titres of different immunoglobulins including $\operatorname{IgM}, \operatorname{IgG}$ and $\operatorname{Ig} \mathrm{A}$.

In the present study the prevalence of Coxsackie B virus infection among patients with myocarditis and dilated cardiomyopathy was detected by using SERION ELISA classic Coxsackie virus IgM. SERION ELISA classic Coxsackie virus $\operatorname{IgM}$ is a qualitative and quantitative solid phase immunoassay for detection of Coxsackie virus group B specific antibiodies. SERION ELISA classic Coxsackie virus IgM is highly specific
(>99). In SERION ELISA classic Coxsackie virus kit highly purified, heat-treated Coxsackie viruses types B1 and B5 are bound to the solid phase. These two serotypes are described as sufficiently cross-reactive to enable heterotypical diagnosis of Coxsackie virus infection. The use of paired serum samples and correlation of clinical findings with laboratory results is essential for diagnosis. Persisting IgM-antibodies can be detected in $30-40 \%$ of patients with myocarditis, in $60-70 \%$ of patients with aseptic meningitis and $30 \%$ of patients with chronic fatigue syndrome. Persisting IgMand IgA-antibodies (> 6 months) may indicate chronic diseases such as relapsing pericarditis or type 1 diabetes.

Since the 1960s, it has been suggested that group B Coxsackie viruses are the most frequent viral etiological agent associated with heart diseases including myocarditis, pericarditis and endocarditis (Burch and Giles 1972; Koontz and Ray 1971; Pongpanich et al. 1983; Ward 2001; Gauntt and Huber 2003), causing more than $50 \%$ of all cases of viral myocarditis (Ali and Abdel-Dayem 2003).

This is the first report on the prevalence of Coxsackie B virus among patients with myocarditis and dilated cardiomyopathy from Chennai, south India. In this study about $76 \%$ of the patients with myocarditis and dilated cardiomyopathy were found to be positive for Coxsackie B virus infections, which is higher than the previous studies worldwide, which reports up to $70 \%$ of the myocarditis and DCM cases with Enterovirus infection (Jin et al., 1990; Why et al., 1994; Martin et al., 1994; Pauschinger et al., 1999; Arbustini et al., 2000; Li et al., 2000; Shirali et al., 2001; Chimenti et al., 2001; Alter et al., 2001, Frustaci et al., 2003; Bowles et al., 2003; Zhang et al., 2004; Angelini et al., 2000; Calabrese et al., 2002).

We found the incidence of Coxsackie $B$ virus infection to be more among adults (82\%) when compared to children (18\%). Coxsackie B virus infection appears to be rare in early childhood, even though these individuals are susceptible to infection (Saphir et al., 1957) and this may be one of the reasons for low incidence of Coxsackie B virus myocarditis in children. The results shows the incidence of Coxsackie $\mathrm{B}$ virus infection among male and female is more or less equal with slight preponderance in females $(52 \%)$ compared to males (48\%). This is in contrast with the previous studies which showed predominance in males (Sainani et al., 1968). The reason for this variation may be due the small sample size in our study.

Studies have demonstrated that the presence of enterovirus or other related viruses in patients with mycocarditis and DCM are associated with a worse outcome (Kuhl et al. 2005; Why et al. 1994). There are reports on successful treatment of Coxsackie B virus and other enterovirus positive patients with antiviral agents like interferon $\beta$ (INF- $\beta$ ), which resolved the viral infection and improved the ventricular function 
(Kuhl et al., 2003). The mortality rate of the patients with myocarditis and DCM in this study was about $6 \%$. Some patients will not respond to the therapy, this is mainly due to the late stage of the infection where there will be high rate of Coxsackie $B$ virus persistence in the heart that cannot be overcome by therapy and associated with worse outcome (Frustaci et al., 2003).

Even though there are contrasting reports worldwide, with some stating that the universal polio vaccination has reduced the overall enterovirus seropositivity and myocarditis by enteroviruses including Coxsackie B virus (Viskari et al. 2004, 2005: Sadeharju et al. 2007), the present study has shown that there is high rate of Coxsackie B virus infections among myocarditis and DCM patients the from Chennai, South India. Hence coxsackie B virus appears to play a major role in the viral myocarditis and DCM.

\section{Conclusion}

a. Viral myocarditis has been recognized as a cause of cardiac dysfunction and is still a challenging disease to diagnose and treat.

b. The incidence and prevalence of Coxsackie B virus in myocarditis and DCM patients have not been reported in south India.

c. This is the first study to report on the prevalence of Coxsackie B virus among patients with myocarditis and dilated cardiomyopathy in Chennai, south india.

d. The prevalence of Coxsackie B virus among myocarditis and dilated cardiomyopathy patients was found to be $75.75 \%$ when tested using an immunoassay specific for IgM antibodies.

e. In this study the prevalence of Coxsackie B virus myocarditis/DCM was found to be more in adults.

f. Diabetes mellitus and coronary artery disease were the predominant co-morbid conditions associated with Coxsackie B virus among myocarditis and dilated cardiomyopathy.

g. The mortality rate among study population is found to be $6 \%$.

h. To conclude this pilot study reports a high prevalence of Coxsackie B virus from Chennai and support its aetiological role in myocarditis and DCM patients. This indicates the importance of monitoring for Coxsackie B virus infections in myocarditis and DCM patients in Chennai, South India and warrants further study.

\section{References}

1. Arbustini E, Porcu E, Bellini O, Grasso M, Pilotto A, Dal Bello B, Morbini P, Diegoli M, Gavazzi A, Specchia G, Tavazzi L. (2000). Enteroviral infection causing fatal myocarditis and subclinical myopathy. Heart 83, 86-90.

2. Chimenti C, Calabrese F, Thiene G, Pieroni M, Maseri A, Frustaci A. (2001). Inflammatory left ventricular microaneurysms as a cause of apparently idiopathic ventricular tachyarrhythmias. Circulation 104, 168-73.
3. Frustaci A, Chimenti C, Calabrese F, Pieroni M, Thiene G, Maseri A .(2003). Immunosuppressive therapy for active lymphocytic myocarditis: virological and immunologic profile of responders versus nonresponders. Circulation 107, 857-63.

4. Jin O, Sole MJ, Butany JW, Chia WK, McLaughlin PR, Liu P, Liew CC. (1990). Detection of enterovirus RNA in myocardial biopsies from patients with myocarditis and cardiomyopathy using gene amplification by polymerase chain reaction. Circulation 82,8-16.

5. Lee FK, Nahmias AJ, Stagno S. (1978). Rapid diagnosis of cytomegalovirus infection in infants by electron microscopy. N Engl J Med 299, 1266-70.

6. Martin AB, Webber S, Fricker FJ, Jaffe R, Demmler G, Kearney D, Zhang YH, Bodurtha J, Gelb B, Ni J et al. (1994). Acute myocarditis. Rapid diagnosis by PCR in children. Circulation 90, 330-9.

7. Pauschinger M, Doerner A, Kuehl U, Schwimmbeck PL, Poller W, Kandolf R, Schultheiss HP. (1999). Enteroviral RNA replication in the myocardium of patients with left ventricular dysfunction and clinically suspected myocarditis. Circulation 99, 889-95.

8. Shirali GS, Ni J, Chinnock RE, Johnston JK, Rosenthal GL, Bowles NE, Towbin JA. (2001). Association of viral genome with graft loss in children after cardiac transplantation. N Engl J Med 344, 1498-503.

9. Why HJ, Meany BT, Richardson PJ, Olsen EG, Bowles NE, Cunningham L, Freeke CA, Archard LC. (1994). Clinical and prognostic significance of detection of enteroviral RNA in the myocardium of patients with myocarditis or dilated cardiomyopathy. Circulation 89,2582 .

10. Zhang H, Li Y, McClean DR, Richardson PJ, Florio R, Sheppard M, Morrison K, Latif N, Dunn MJ, Archard LC (2004). Detection of enterovirus capsid protein VP1 in myocardium from cases of myocarditis or dilated cardiomyopathy by immunohistochemistry: further evidence of enterovirus persistence in myocytes. Med Microbiol Immunol (Berl).193:109-14

11. Bowles NE, Ni J, Kearney DL, Pauschinger M, Schultheiss HP, McCarthy R, Hare J, Bricker JT, Bowles KR, Towbin JA .(2003). Detection of viruses in myocardial tissues by polymerase chain reaction. Evidence of adenovirus as a common cause of myocarditis in children and adults. J Am Coll Cardiol 42, 466-72.

12. Calabrese F, Rigo E, Milanesi O, Boffa GM, Angelini A, Valente M, Thiene G. (2002). Molecular diagnosis of myocarditis and dilated cardiomyopathy in children: clinicopathologic features and prognostic implications. Diagn Mol Pathol 11,212-21.

13. Saphir 0, Cohen NA. (1957). Arch Pathol 64, 446-456. Sainani GS, Krompotic E, Slodki SJ. (1968). Myocarditis in infancy. Adult heart disease due to the Coxsackie virus B infection. Medicine 47, 133-47.

14. Kuhl U, Pauschinger M, Seeberg B, Lassner D, Noutsias M, Poller W, Schultheiss HP. (2005). Viral persistence in the myocardium is associated with progressive cardiac dysfunction. Circulation 112,1965-70. 